\title{
EL ESPAÑOL EN LA EDUCACIÓN BRASILEÑA: DESDE EL HISTÓRICO NACIONAL HASTA LAS ESPECIFICIDADES EN LAS IES DE RIO GRANDE DO NORTE
}

\author{
O ESPANHOL NA EDUCAÇÃO BRASILEIRA: DO HISTÓRICO \\ NACIONAL ÀS ESPECIFICIDADES NAS IES DO RIO GRANDE DO \\ NORTE
}

\author{
Tatiana Lourenço de Carvalho* \\ José Veranildo Lopes da Costa Junior**
}

\begin{abstract}
Resumen: Aunque fue la ley 11.161/05 que dio más visibilidad al idioma de Cervantes en Brasil, es importante decir que tenemos un extenso histórico acerca de la oferta de cursos de lengua española en nuestro país, y que empieza en 1919, cuando el Colegio Pedro II, en Rio de Janeiro, seleccionó un profesor para impartir clases de esta lengua neolatina. Desde entonces, el español ha pasado por movimientos de exclusión e inclusión en el currículo nacional. En este artículo, buscamos presentar la evolución histórica de la presencia del español en la educación brasileña, una reflexión sobre el contexto de enseñanza y aprendizaje del castellano en las instituciones de enseñanza superior (IES) del estado de Rio Grande do Norte y poner de manifiesto algunos de los motivos por los cuales los brasileños deben aprender español. Como resultado, entre otras cosas, vale resaltar dos puntos: que la formación inicial de calidad ofrecida por instituciones públicas de Rio Grande do Norte contribuye con la difusión del castellano en el estado y que la apertura de posibilidades de investigación en cursos de posgrado que reciben profesores de español funciona como un importante mecanismo de formación continuada para los docentes de esta lengua.
\end{abstract}

Palabras clave: Enseñanza de español. Histórico en Brasil. Enseñanza superior en Rio Grande do Norte.

Resumo: Ainda que a lei 11.161/05 tenha sido a que mais deu visibilidade ao idioma de Cervantes no Brasil, é importante dizer que temos um extenso histórico sobre a oferta de cursos de língua espanhola no nosso país, que começa em 1919, quando o Colégio Pedro II, no Rio de Janeiro, selecionou um professor para ministrar aulas dessa língua neolatina. Desde então, o espanhol tem passado por movimentos de exclusão e inclusão no currículo nacional. Neste artigo, buscamos apresentar a evolução histórica da presença do espanhol na educação brasileira, uma reflexão sobre o contexto de ensino e aprendizagem do castelhano nas instituições de ensino superior (IES) do estado do Rio Grande do Norte e destacar alguns dos motivos pelos quais os brasileiros devem aprender espanhol. Como resultado, entre outras coisas, vale ressaltar dois pontos: que a formação inicial de qualidade ofertada por instituições públicas do Rio Grande do Norte contribui com a difusão do castelhano no estado e que a abertura de possibilidades de investigação em cursos de pós-graduação que recebem professores de espanhol funciona como um importante mecanismo de formação continuada.

Palavras-chave: Ensino de espanhol. Brasil. Rio Grande do Norte.

\section{Introducción}

El espacio (o el apagamiento) de una asignatura en el currículo de las escuelas no dice respecto a una elección exclusivamente pedagógica, sino política. En este sentido, la oferta de la lengua española en instituciones educacionales de nuestro país ha vivido movimientos de exclusión e inclusión, debido a un conjunto de políticas

\footnotetext{
* Professora Adjunta do Departamento de Letras Estrangeiras da Universidade do Estado do Rio Grande do Norte (UERN). E-mail: tatianacarvalho10@yahoo.com.br

** Professor Adjunto do Departamento de Letras Estrangeiras da Universidade do Estado do Rio Grande do Norte (UERN). E-mail: jveranildo@ hotmail.com
} 
lingüísticas celebradas a lo largo de la historia. Guimarães (2011), por ejemplo, menciona que en 1919 hubo la primera inclusión del castellano en el sistema educativo brasileño, cuando se aprobó la creación de una asignatura de español en el Colegio Pedro II, en Rio de Janeiro, mediante un tratado firmado con el gobierno de Uruguay.

Sabemos de la existencia de muchos tratados y convenciones que, de un modo general, buscan insertar la lengua española en las escuelas brasileñas. La historia del español en el contexto de enseñanza del país puede ser leída en las investigaciones de Sedycias (2005), Paraquett (2006), Guimarães (2011), Carvalho (2018), entre otros. Sin embargo, no hay duda que, en relación a una difusión de la lengua castellana en el currículo educacional en Brasil, fue la aprobación, el 5 de agosto de 2005, de la ley 11.161/05, que más dio visibilidad a este idioma en todo el territorio nacional.

A partir de entonces, el español gozó de una institucionalización, marcada por la ley propiamente dicha, pero también por la presencia de una discusión sobre currículos plurilingües en los principales documentos oficiales en el contexto de la educación. Para citar un ejemplo, los Parâmetros Curriculares Nacionais (PCN) mencionan que:

No âmbito da LDB e do parecer do CNE, as línguas estrangeiras modernas recuperaram, de alguma forma, a importância que durante muito tempo lhes foi negada. Consideradas muitas vezes e de forma injustificada, como pouco relevante, elas adquirem, agora, a configuração de disciplina importante, como qualquer outra, do ponto de vista da formação do aluno (BRASIL, 2000, p. 11).

Este documento oficializa la importancia de las lenguas (en el plural) en el currículo nacional y discute que, por mucho tiempo, los idiomas fueron entendidos como asignaturas de poca relevancia para la formación de los estudiantes brasileños. Además de eso, el documento también aclara su concepción de políticas lingüísticas:

\footnotetext{
Nesse sentido, vários pontos merecem atenção. Um deles diz respeito ao monopólio linguístico que dominou nas últimas décadas, em especial nas escolas públicas. Sem dúvida, a aprendizagem de Língua Inglesa é fundamental no mundo moderno, porém, essa não deve ser a única possibilidade a ser oferecida ao aluno. Em contrapartida, verificou-se, nos últimos anos, um interesse crescente pelo estudo do castelhano. De igual maneira, entendemos que tampouco deva substituir-se um monopólio linguístico pelo outro (BRASIL, 2000, p. 25).
}

Los PCN (2000) ofrecían al estudiante la oportunidad de aprender dos lenguas extranjeras, el inglés y el español, o el inglés y el francés, por ejemplo, dando a la comunidad escolar la posibilidad de elegir cuáles idiomas estudiar, de acuerdo con sus intereses y expectativas.

En función de las crisis políticas en Brasil, principalmente a partir del impeachment de Dilma Rousseff, la educación brasileña empezó a vivir un conjunto de cambios en sus documentos educacionales y en la política lingüística adoptada actualmente, como nos muestra Silva Junior e Eres Fernández (2019a; 2019b) en los artículos "Ausência da língua espanhola na Base Nacional Comum Curricular: quais implicações esperar?" y "A docência de línguas estrangeiras e as políticas recentes para a formação de professores"; Carvalho (2020) en "Possibilidades e (in)viabilidades do espanhol na educação básica: as leis da metade" o Carvalho e Costa Junior (2020) en 
"Resistência e políticas linguísticas para o ensino de espanhol no Ceará: o cenário pósrevogação da lei 11.161/05", por ejemplo.

El principal cambio en la educación brasileña se da a partir de la publicación de la Base Nacional Comum Curricular (BNCC) (BRASIL, 2018) que trae en su estructura una política lingüística excluyente al mencionar solo el inglés como lengua extranjera que debe ser enseñada en las escuelas. Eso significa decir que la BNCC impone al estudiante cuál lengua estudiar sin llevar a cabo los intereses de los entornos que forman parte de la comunidad escolar.

Además de un contexto de monolingüismo impuesto por ese último documento mencionado, cabe destacar un intento de la BNCC en uniformizar la enseñanza brasileña a partir del propio nombre del documento: i. Base; ii. Nacional; iii- Común. Esas tres palabras pasan la idea de la construcción de un currículo homogéneo, "igual para todos".

Sin embargo, sabemos que Brasil es un país marcado por las desigualdades sociales (y educacionales), y es también un país de dimensiones continentales, lo que resalta las diferentes necesidades conforme su posición geográfica y, consecuentemente, los aspectos culturales específicos de cada una de las cinco regiones del país. Así, ellas poseen necesidades educativas diferenciadas. Si, por ejemplo, Amapá está más cerca de la Guyana Francesa y los estudiantes de este estado sienten la necesidad de estudiar el francés, no tiene sentido que la BNCC les obligue a estudiar el inglés. De igual modo, si Rio Grande do Sul comparte fronteras con Uruguay y Argentina, es natural que sus estudiantes deseen aprender castellano, pero la BNCC impone el inglés como única lengua extranjera a ser aprendida obligatoriamente en el país. Así, se ve claramente la imposibilidad de creación de un currículo homogéneo en un país cuyas las necesidades regionales educacionales son tan heterogéneas.

Diferentemente de la BNCC, los PCN ponían de manifiesto que:

Não se deve pensar numa espécie de unificação do ensino, mas, sim, no atendimento às diversidades, aos interesses locais e às necessidades do mercado de trabalho no qual se insere ou virá a inserir-se o aluno (BRASIL, 2000, p. 27).

Considerando, pues, la presencia de las lenguas extranjeras (siempre en el plural) en el currículo nacional y en sus documentos orientadores, este artículo tiene como uno de sus objetivos tratar del contexto de la enseñanza y el aprendizaje de español en las instituciones de enseñanza superior (IES) en el estado de Rio Grande do Norte, buscando señalar la necesidad de oferta de carreras de grado y posgrado en instituciones públicas para la difusión del castellano en este estado nordestino. Para tanto, el artículo trae un breve histórico de la enseñanza de español en Brasil, en el apartado que sigue. Luego, algunos datos acerca de la presencia de la lengua de Cervantes en instituciones públicas de nivel superior en el estado, en donde trabajamos como profesores actualmente. Por fin, actualizamos la importancia de aprender español hoy en día.

\section{Un histórico sobre la presencia de la enseñanza de español en Brasil}

En lo que dice respecto a la presencia del castellano en instituciones educacionales brasileñas, el primer registro de la inserción del español en una escuela se dio a partir de la oposición pública que seleccionó, en 1919, el primer profesor 
catedrático de español del Colegio Pedro II, en Rio de Janeiro, el filólogo Antenor Nascentes (GUIMARÃES, 2011).

Ese docente, lingüista y lexicógrafo, estuvo durante nueve años trabajando con la enseñanza del idioma castellano en la dicha escuela, cuando se transfirió de la cátedra de español para la de portugués, por medio del decreto de 23 de enero de 1928. El dato nos parece importante para señalar un punto particular acerca del español en Brasil: tenemos más de 100 años de enseñanza de ese idioma neolatino en nuestro país, lo que revela la fuerza (y la relevancia) que tiene el castellano para la educación brasileña.

Otro aspecto digno de destaque es la importancia, para la introducción de la lengua española en las escuelas públicas brasileñas, de la Reforma Capanema, de 1942 que proponía que todos los estudiantes, desde el llamado Ginásio hasta el Científico o Clássico, deberían estudiar latín, inglés o español. La prioridad dada a estos tres idiomas duró diecinueve años.

Con la Lei de Diretrizes e Bases da Educação Nacional (LDB ${ }^{1}$ ) de 1961, hubo una reducción de la oferta del español y del latín, compensada por la presencia de otras lenguas modernas en el país, como el italiano, el alemán e, incluso, el japonés. Todas ellas de amplia importancia cultural debido al movimiento migratorio de su población nativa a Brasil en aquel entonces. Hoy en día, esas lenguas siguen olvidadas por los documentos oficiales (principalmente por la BNCC) que no incentiva un plurilingüismo en las escuelas.

En 1996, se creó la nueva Lei de Diretrizes e Bases da Educação Nacional (LDB) y en ella simplemente se mencionó que sería incluida una lengua moderna como asignatura obligatoria, elegida por la comunidad escolar, y una segunda en carácter optativo, según las posibilidades de la institución. En este contexto, el inglés, como lengua de prestigio internacional, por motivos políticos y económicos, mantuvo garantizado su puesto de primer lugar en las "preferencias" de la comunidad escolar una vez que el gobierno de Brasil no fomentaba la importancia de las relaciones comerciales y culturales con los países vecinos. En segundo lugar, sería el español, en función de su importancia para el país, puesto que se encontraba en gran actividad de utilización durante la creación del MERCOSUR ${ }^{2}$ a principios de los años 90.

No obstante, pese a que el español es el idioma hablado por casi todos los países que componen el bloque económico de la América del Sur, la historia de la educación en tierras brasileñas demuestra que, hasta el período de la LDB mencionada anteriormente, no había disponibilidad, en la carga horaria de las escuelas, para la enseñanza de esa lengua. Tampoco recursos humanos y materiales para agregar, entre las asignaturas, un segundo idioma extranjero. Esto significa que, en tal período, predominaba (por no decir monopolizaba) en la enseñanza de lenguas extranjeras de las escuelas brasileñas, el inglés. Esto siempre se dio, también, debido al factor político y

\footnotetext{
${ }^{1}$ La Lei de Diretrizes e Bases da Educação (LDB) define y regula el sistema de educación brasileño con base en los principios presentes en la Constitución. La primera LDB fue creada en 1961, seguida por una versión de 1971, que estuvo en vigor hasta la promulgación de la más reciente, en 1996.

${ }^{2}$ El MERCOSUR nació el día 26 de marzo de 1991, con el Tratado de Asunción, constituyendo un mercado común entre la República Argentina, la República Federativa de Brasil, la República del Paraguay, la República Oriental del Uruguay, más tarde, la República Bolivariana de Venezuela, y el Estado Plurinacional de Bolivia (en proceso de adhesión), con los cuales comparten, en común acuerdo, los valores democráticos y pluralistas, defensores de las libertades fundamentales, de los derechos humanos, de la protección del medio ambiente, del desarrollo sostenible, de la seguridad jurídica, del combate a la pobreza, del desarrollo económico y de la igualdad social. Disponible en: $<$ http://www.mercosur.int/innovaportal/v/7823/2/innova.front/paises-del-mercosur $>$. Acceso el 7 de jul. 2020.
} 
económico que llevó este idioma a ser considerado lengua predominante, principalmente por las políticas lingüísticas que eran, en gran medida, preformadas para satisfacer a los intereses de los Estados Unidos en Brasil.

Observamos la existencia de un monopolio del inglés en el currículo nacional desde entonces, una vez que pocas políticas lingüísticas fueron creadas para incentivar la formación de profesores de español (con excepción de la ley 11.161/05), de italiano, de francés o de alemán, por ejemplo, en nuestro país. Por otro lado, gran parte de esas políticas parecen fomentar la formación exclusiva de profesores de inglés, con el argumento de que esta sería la lengua más importante para que un estudiante brasileño aprendiera, aunque teniendo en cuenta que Brasil comparte fronteras con un número expresivo de países hispánicos.

La ley que rigió el sistema educacional de Brasil, desde 1996 hasta 2017, fue la LDB en la que se afirmaba que el aprendizaje de las lenguas, no solamente la materna sino también las extranjeras, era derecho de todos. La proximidad de Brasil con los países hispanohablantes de la América del Sur, el aumento de las relaciones comerciales impulsadas por el MERCOSUR, además de las buenas relaciones comerciales con España, hicieron que el castellano pasara a ocupar un lugar de prestigio en la educación brasileña, llevando el entonces presidente Luis Inácio Lula da Silva, el 05 de agosto de 2005, a convertir en obligatoria, a través de la ley $\mathrm{n}^{\mathrm{o}} 11.161 / 2005$, la oferta de la lengua española en el currículo de la enseñanza secundaria de las escuelas brasileñas (CARVALHO, 2018). A seguir, reproducimos el texto integral de la ley en cuestión:

Art. $1^{\circ} \mathrm{O}$ ensino da língua espanhola, de oferta obrigatória pela escola e de matrícula facultativa para o aluno, será implantado, gradativamente, nos currículos plenos do ensino médio.

$\S 1^{\circ} \mathrm{O}$ processo de implantação deverá estar concluído no prazo de cinco anos, a partir da implantação desta Lei.

$\S 2^{\circ}$

É facultada a inclusão da língua espanhola nos currículos plenos do ensino fundamental de $5^{\mathrm{a}}$ a $8^{\mathrm{a}}$ séries.

Art. $2^{\circ} \mathrm{A}$ oferta da língua espanhola pelas redes públicas de ensino deverá ser feita no horário regular de aula dos alunos.

Art. $3^{\circ}$ Os sistemas públicos de ensino implantarão Centros de Ensino de Língua Estrangeira, cuja programação incluirá, necessariamente, a oferta de língua espanhola.

Art. $4^{\circ}$ A rede privada poderá tornar disponível esta oferta por meio de diferentes estratégias que incluam desde aulas convencionais no horário normal dos alunos até a matrícula em cursos e Centro de Estudos de Língua Moderna.

Art. $5^{\circ}$ Os Conselhos Estaduais de Educação e do Distrito Federal emitirão as normas necessárias à execução desta Lei, de acordo com as condições e peculiaridades de cada unidade federada.

Art. $6^{\circ}$ A União, no âmbito da política nacional de educação, estimulará e apoiará os sistemas estaduais e do Distrito Federal na execução desta Lei.

Art. $7^{\circ}$ Esta Lei entra em vigor na data da sua publicação (BRASIL, 2005). 
Este ha sido uno de los hechos más importantes para que Brasil fuera uno de los países en donde el estudio del español experimentó un amplio crecimiento a comienzos del siglo XXI. Sin lugar a duda, la promulgación de la ley de obligatoriedad de la enseñanza de este idioma en las escuelas brasileñas fue una medida que obligó a todas las escuelas de enseñanza secundaria, ya fueran públicas o privadas, a ofrecer la posibilidad de aprender el idioma castellano en el horario lectivo. En un artículo recién publicado, Carvalho (2020) afirma que:

\begin{abstract}
Possíveis motivações para sua promulgação (a Lei 11.161/05) referem-se à localização geopolítica do Brasil em meio à América hispanofalante; ao fortalecimento do bloco econômico MERCOSUL e ao processo de crescimento econômico brasileiro em meio a um cenário de crise mundial (cf. Carvalho, 2017). As condições de produção da referida Lei ancoram-se na política econômica neoliberal, de ideologia capitalista, que concebe a educação de acordo com a lógica de mercado, logo, devendo funcionar à sua semelhança (CARVALHO, 2020, p. 683 acréscimos nossos).
\end{abstract}

Conforme la cita, esta ley, para la autora, es un acontecimiento discursivo singular una vez que podemos entender que la ley cambiaba, a partir del discurso jurídico, la idea de que el español, cuando comparado con el inglés, era considerado una asignatura de menor importancia.

Sin embargo, a pesar de todo un contexto favorable para la presencial del castellano en Brasil, es importante destacar que la enseñanza de esta lengua nunca se implantó de modo satisfactorio en las escuelas tanto de la red pública como privada en Brasil. Así:

\begin{abstract}
Nos elementos linguísticos da legislação, a presença de sintagmas que indicam o caráter injuntivo da lei, como: "deverá", "será", "implementarão", "emitirão", "estimulará", "apoiará", expressos por verbos no futuro, apontam para a perspectiva de efetiva implementação da lei pelas escolas e objetivam assegurar que a implementação ocorrerá. A ideia de progressão expressa no advérbio "gradativamente", empregado no artigo $1^{\circ}$, deu margem às diversas interpretações sobre o modo como a disciplina Língua Espanhola deveria ser inserida nos currículos plenos do ensino médio (EM), ou seja, em todas as séries até 2010. A textualização da passagem "gradativamente, nos currículos plenos do ensino médio", do artigo $1^{\circ}$, associada ao "processo de implantação deverá estar concluído no prazo de cinco anos, a partir da implantação desta Lei”, expressos na Lei $\mathrm{n}^{\circ} 11.161 / 2005$, em alguns contextos do âmbito escolar, foi entendida como oferta da disciplina em uma série apenas do EM e a implantação em alguns casos foi a partir do ano de 2010, prazo final para que a lei fosse colocada em prática (CARVALHO, 2020, p. 685).
\end{abstract}

El contexto resaltado en la cita anterior se dio, entre otros factores, debido a la mala interpretación de la ley 11.161/05 por parte de los gobernantes e incluso de los gestores de algunas escuelas, lo que generó pérdidas significativas que acabaron por perjudicar la inserción del español en algunos contextos escolares. Otro factor importante tiene que ver con la dificultad para la contratación de profesores cualificados por tratarse, en gran proporción, de una relativa novedad curricular en aquel entonces. ${ }^{3}$

\footnotetext{
${ }^{3}$ Pese a esas dificultades señaladas en este artículo acerca de la inclusión del español, hubo importantes marcos en la historia de la enseñanza de esta lengua en Brasil tales como el PIBIC, el PIBID, el PNLD y el ENEM. Pero de esto trataremos detalladamente en trabajos futuros.
} 
Cuando finalmente el país empezó a avanzar algo en la formación de excelencia y capacitación de un mayor número de docentes de español licenciados en una carrera de Letras Español, tuvo lugar la crisis económica mundial que afectó directamente a Brasil. Tal contexto culminó con un golpe de estado que retiró de su cargo a la presidenta electa, Dilma Rousseff.

En virtud del cambio de gobierno, se instauró en Brasil una serie de medidas de recortes de gastos. Entre ellos, las que interfirieron directamente en la educación, lo que dio lugar a la ley federal 13.415/17, que, entre otras acciones, revocó la ley 11.161/05. Tales medidas quitaron la obligatoriedad de la oferta de asignaturas como el español, la filosofía y la sociología, por ejemplo, desde una reforma de la enseñanza que llevó a la publicación de la BNCC, el 2018. De acuerdo con este documento, el español ha perdido su carácter de obligatoriedad, lo que viene generando una serie de manifiestos y protestas por parte de estudiantes y profesores de todo el país con el objetivo de reparar esta injusticia en consecuencia de una política lingüística excluyente y monolingüe.

A seguir, presentamos los datos acerca de la realidad de la formación de profesores de lengua española en tres instituciones de enseñanza superior (IES) del estado de Rio Grande do Norte.

\section{La presencia del español en instituciones de enseñanza superior (IES) de Rio Grande do Norte}

En el estado de Rio Grande do Norte, el español es ofertado como carrera de grado en licenciatura en tres instituciones de enseñanza superior (IES). La Universidade do Estado do Rio Grande do Norte (UERN) tiene la carrera de licenciatura en LetrasEspañol en las ciudades de Mossoró, desde el 2000, y Pau dos Ferros, desde el 2007, en la modalidad presencial. La Universidade Federal do Rio Grande do Norte (UFRN) ofrece la misma carrera en las ciudades de Natal y Currais Novos, desde el 2009, en la modalidad presencial. Mientras tanto, el Instituto Federal de Educação, Ciência e Tecnologia (IFRN), cuenta con la carrera de formación de profesores de lengua española en la ciudad de Natal, en la modalidad presencial, desde el 2006, y también oferta la misma carrera en la modalidad de Educación a Distancia (EaD), desde el 2010, en diferentes polos de apoyo distribuidos en otras ciudades del estado, tales como Caraúbas, Currais Novos, Grossos, Parnamirim, Marcelino Vieira, Natal, Lajes, Guamaré y São Gonçalo do Amarante.

Podemos afirmar, a partir de las posibilidades de formación en español presentadas aquí y por el contacto que tenemos dentro del estado con el colectivo docente, que las instituciones públicas ocupan especial protagonismo en la formación de profesores de lengua española. Tras concluir su carrera, los docentes graduados en estas IES, en su gran mayoría, pasan a trabajar no solo en el estado potiguar, pero también están insertados en escuelas y universidades de Paraíba y Ceará, estados fronterizos de Rio Grande do Norte.

De acuerdo con la presentación disponible en el sitio web de la $\mathrm{UERN}^{4}$, en la carrera de Letras-Español, de Mossoró, el principal objetivo es formar profesionales interculturalmente competentes, capaces de interactuar, de modo crítico, con el lenguaje, especialmente, verbal, en contextos orales y escritos, y conscientes de su inserción en la sociedad y de las relaciones con el otro.

4 Disponible en <http://www.uern.br/cursos/servico.asp?fac=FALA\&cur_cd=1003203\&item=curso> Acceso el 7 de agosto de 2019. 
La carrera de Letras-Español de la UFRN, de Currais Novos, a su vez, tiene el objetivo de formar profesores de castellano que puedan actuar en instituciones de enseñanza fundamental, media, en la Educación de Jóvenes y Adultos (EJA), en la educación especial, técnica y profesional, en la educación indígena, del campo y en la educación a distancia (EaD) (PPC/UFRN, 2018).

El proyecto pedagógico de la carrera presencial del IFRN, en Natal, menciona como objetivo central formar el profesor a partir de un saber plural, desde la internacionalización de conocimientos específicos del área, además de los pedagógicos y experimentales (PPC/IFRN, 2018). Ya su carrera de la modalidad a distancia nasce con la función de interiorizar la formación de profesores, utilizando las tecnologías como herramientas de inclusión digital y de ampliación de la oferta institucional (PPC/IFRN, 2012).

Al traer informaciones sobre algunas carreras de Letras-Español en el estado, podemos decir que tenemos muchas oportunidades de formación de profesores de castellano en Rio Grande do Norte (tanto en la modalidad presencial, cuanto a distancia), lo que significa considerar que hay interés de la comunidad en estas carreras, ya que cada uno de los grados nacen a partir del presupuesto básico de que haya un perfil de estudiantes que se interese por la formación en Letras-Español a nivel superior.

A parte de las carreras ofrecidas en el grado, la UERN, en la ciudad de Pau dos Ferros, tiene tres cursos de posgrados: un máster en Enseñanza (Programa de Pósgraduação em Ensino - PPGE), un máster y un doctorado en Letras (Programa de Pósgraduação em Letras - PPGL) y un máster profesional (Programa de Pós-graduação Profissional em Letras - PROFLETRAS). Ya el campus de Mossoró ofrece dos posgrados: un máster en Ciencias del Lenguaje (Programa de Pós-graduação em Ciências da Linguagem - PPGCL) y un máster profesional en Letras (Programa de Pós-graduação Profissional em Letras - PROFLETRAS). La UFRN, a su vez, en Natal, ofrece un máster y un doctorado en Estudios del Lenguaje (Programa de Pósgraduação em Estudos da Linguagem - PPGEL). El IFRN tiene un máster en Enseñanza (Programa de Pós-graduação em Ensino - PPGE) y un máster en Educación Profesional (Programa de Pós-graduação de Educação Profissional). Además, hay, en esta institución, algunos cursos de posgrados Lato sensu como, por ejemplo, la Especialización en Literatura y Enseñanza.

Los estudiantes de Letras-Español que desean hacer estudios especializados en el área, pueden hacer selección en algunos de los programas de posgrado citados anteriormente. Sin embargo, se observa la necesidad de posgrados específicos en los estudios hispánicos. Actualmente, en el contexto nacional, solo tenemos el Programa de Posgrado en Letras Neolatinas (máster y doctorado) de la Universidade Federal de Rio de Janeiro y el Programa de Posgrado en Letras - Lengua Española y Literaturas Españolas (máster y doctorado) de la Universidade de São Paulo, que ofertan esa formación específica. Estas son las dos únicas IES que ofrecen cursos especializados en los estudios hispánicos de posgrado lo que resalta la realidad de carencia, no solo en Nordeste, sino en todas las demás regiones e incluso demás universidades de Sudeste del país.

Sin embargo, los programas de posgrado de las universidades potiguares ya cuentan con estudios de disertación y tesis defendidos en el área de español. Si bien, lo que podemos notar es que, todavía, hay un número pequeño de docentes graduados en español que actúan en la formación de investigadores de máster y de doctorado en las instituciones de Rio Grande do Norte, aunque otros profesores - de áreas más generales, 
como Lingüística Aplicada y Teoría de la Literatura - orientan investigaciones que tratan de estudios de lengua española.

La Universidade do Estado do Rio Grande do Norte, por ejemplo, cuenta, actualmente, con un profesor específico del área de lengua española que orienta disertaciones en el Programa de Pós-Graduação em Ciências da Linguagem, en Mossoró. La UFRN tiene un número de tres profesores específicos del área del español que actúan en el Programa de Pós-Graduação em Estudos da Linguagem, en la ciudad de Natal. El Instituto Federal de Educação, Ciência e Tecnologia (IFRN), todavía, no tiene profesores de la lengua castellana trabajando en el posgrado.

Aunque el número de docentes de castellano en el posgrado es pequeño, es importante mencionar dos puntos: i) la carrera de nivel superior de español en nuestro país es, considerablemente, reciente, principalmente en el Nordeste de Brasil. Muchos de los actuales profesores de las universidades públicas de Rio Grande do Norte están todavía en proceso de doctoramiento. A la medida que los docentes logren el título de doctorado, podrán dirigir trabajos de investigación a parte de los desarrollados en las carreras universitarias en los programas de posgrado. ii) Hay diversos estudiantes que hicieron sus investigaciones bajo la dirección de otros profesores de diferentes áreas que no es la de español. Para citar un ejemplo, la carrera de Letras-Español de Pau dos Ferros, solamente el 2018, formó su primera profesora de español como doctora y el segundo doctor del grupo de profesores de ELE, el 2020. Tal contexto nos hace recordar que esta realidad todavía necesita mejorar en este estado, conforme ya comentaban Gomes, Falcão y Irineu (2016, p. 296) acerca de que es un desafío ofrecer:

\footnotetext{
formação continuada para esses docentes, em nível de pós-graduação, tanto lato sensu, como stricto sensu. Ainda faltam políticas públicas, tanto dos gestores como das próprias IES, que incentivem a formação continuada dos egressos desses cursos de licenciatura em E/LE.
}

Considerando tal contexto, al graduado en Letras-Español del estado de Rio Grande do Norte que quiera seguir su formación en los estudios de posgrados cabe adaptarse al trabajo con profesores de otras áreas o migrar a otros estados o, incluso, países si quieren tener una formación y vivencia de estudios de la lengua en cuestión de forma más especializada.

Por fin, los datos presentados en este apartado, aunque representen, de modo general, la realidad actual (hasta el 2020) del español en contextos universitarios potiguares, resaltan también que el campo de formación en la educación superior y en los programas de posgrado están abiertos a la investigación en el área de esta lengua y sus literaturas. Sin embargo, hace falta incorporar profesores específicos del área para dirigir las investigaciones del contexto hispánico.

Siguiendo con las reflexiones, ahora, acerca de la importancia de aprender español en nuestro país, nos profundizamos en este tema en el apartado a continuación.

\section{3. ¿Por qué aprender español en Brasil?}

Fernández (2005, p. 30) afirma que "la formación de profesores de español es una de las grandes deudas que el gobierno de Brasil tiene contraídas con la sociedad brasileña". Eso se debe al hecho de que, cuando no se fomenta la enseñanza de 
castellano en nuestro país, el gobierno nos deja aislados de Latinoamérica y del mundo plurilingüe.

Considerando el actual contexto político que redujo el español, entre otras asignaturas, a un espacio de marginalización en la nueva propuesta curricular (BNCC, 2018), cabe volver a la siguiente cuestión: ¿Por qué aprender español hoy en Brasil? Hay muchos autores que traen esa discusión en sus estudios, a ejemplo de Sedycias (2005), que presenta 10 razones para estudiar la lengua castellana en nuestro país. En este artículo, aunque de forma rápida, se nos toca actualizar ese importante debate.

Entre otros motivos, el aprendizaje del idioma español en Brasil se justifica desde nuestra localización geográfica, ya que somos los únicos hablantes de portugués, como primera lengua, en Latinoamérica. La enseñanza de la lengua española en nuestro país, por lo tanto, puede promover el fortalecimiento de las cuestiones económicas y el estrechamiento de las relaciones culturales con los países vecinos (CARVALHO, 2018; SEDYCIAS, 2005).

El castellano está presente en los cinco continentes, en 21 países, teniendo el status de lengua internacional. Es también idioma oficial de la Unión Europea y del MERCOSUR. Es la lengua de la mayoría de los países de Latinoamérica, continente con el cual compartimos procesos históricos, geográficos, socioculturales y de identidad. Es un idioma muy utilizado en las publicaciones científicas internacionales. Es la segunda lengua de comunicación en Estados Unidos, pues cerca de 58 millones de hispánicos viven en aquél país. Es la lengua más buscada en el ENEM (Exame Nacional do Ensino Médio - Brasil), alrededor de $60 \%$ de los candidatos optan por el español. Es una lengua estratégica para el Nordeste brasileño, pues facilita el desarrollo turístico (y económico) de la región.

Además de las razones mencionadas anteriormente, cuando consideramos el español en el contexto educacional, no podemos olvidar dos motivos que resaltan la importancia de la enseñanza de esta lengua neolatina en la educación básica y superior. El estudiante que, desde la enseñanza básica tiene acceso al español, podrá lograr becas de estudio en España y en Latinoamérica fornecidas tanto por el gobierno brasileño, como por los gobiernos de los países hispánicos. Estas estancias en el extranjero posibilitan a este estudiante un alargamiento de su visión de mundo a partir del contacto con culturas diferentes de la suya. Aquí, el aprendizaje de la lengua asume un papel importante en la formación del ciudadano, ya que aprender una lengua es también conocer y actuar con culturas diferentes.

El estudiante que llega a la educación superior comunicándose en español tendrá más posibilidades de acceso al conocimiento. Además de referencias escritas en lengua castellana, diversas instituciones de enseñanza superior ya ofrecen clases ministradas en español. Un caso de destaque, en Brasil, es la Universidade Federal da Integração Latino-americana (UNILA), ubicada en Foz de Iguazú, que oferta cursos en las más distintas áreas del saber en lengua española.

En los programas de posgrado, para citar otro ejemplo, es necesario comprobar suficiencia en un idioma extranjero para ascender a los cursos de máster y dos lenguas extranjeras para cursar un programa de doctoramiento. En la mayoría de las universidades, el español es una de las lenguas aceptadas en exámenes de competencia lingüística en idiomas extranjeros. Es también interés de los programas de posgrado incentivar la internacionalización y el intercambio académico de sus estudiantes en universidades extranjeras, entre ellas las de los demás países latinoamericanos y las casi milenarias universidades españolas. Para recibir una beca o para cursar una estancia en 
uno de estos países, es necesario conocer bien su idioma nativo. Otra vez, el español muestra su importancia.

En este apartado, presentamos algunos motivos para aprender español en los días actuales, llevando en cuenta el contexto político, económico y académico en el cual estamos insertados como docentes e investigadores. De este modo, recordamos que el mundo contemporáneo exige, cada vez más, interacción con culturas diversas. El español se transforma en una alternativa lingüística que nos permite establecer contacto con el mundo. Por fin, aquel que no aprende lenguas extranjeras, posiblemente, estará aislado del contexto internacional y de todas las posibilidades que el aprendizaje de una lengua se nos ofrece en este mundo cada vez más "cercano" en diferentes contextos y potencializados por el medio digital.

\section{Consideraciones finales}

El trabajo en cuestión fue elaborado con el objetivo de analizar parte de la historia sobre la enseñanza de español en Brasil. Consideramos importante tratar de tal recurrido histórico de la presencia de este idioma en instituciones educativas brasileñas para comprender el proceso de expansión de la lengua castellana en el país, más específicamente de los últimos años en el estado del Rio Grande do Norte, contexto que acompañamos más de cerca el trabajo de enseñanza de esta lengua en las tres instituciones de enseñanza superior (IES) que ofrecen la carrera de Letras Español, la UERN, la UFRN y el IFRN.

Presentamos, todavía, algunos motivos que resaltan la importancia de aprender español, en Brasil, considerando desde nuestra localización geográfica, compartiendo la frontera con países cuyo el español es el idioma materno de la mayoría, hasta el reconocimiento de que vivimos en un mundo contemporáneo que exige, cada vez más, interacción con culturas diversas y aquel que no aprende lenguas extranjeras, posiblemente, estará aislado del contexto internacional y de las posibilidades que el aprendizaje de idiomas ofrece en este mundo cada vez más globalizado.

Ante la crisis económica y política actual, la integración y el fortalecimiento de las relaciones con los demás países y la inserción de Brasil en el contexto global de relaciones respetuosas se ven fragilizadas y apartadas del ideal del multilingüismo que requieren las relaciones internacionales y las intenciones diplomáticas. Esto se viene manteniendo en el país, a partir de cuándo empezó el proceso que llevó al golpe que destituyó la presidenta elegida democráticamente, Dilma Rousseff, el año de 2016, de su mandato y llevó a la presidencia el vice Michel Temer. Este, entre otras prácticas de retrocesos, empezó la retirada de la oferta del español de las escuelas brasileñas.

Delante de tales hechos y de la legislación brasileña educativa actual, merece la pena reforzar la crítica acerca de las políticas públicas educacionales (y lingüísticas) de Brasil, que no deben dejar de lado la importancia de la formación social de su población. En este sentido, es necesario, todavía, fortalecer y ampliar la discusión sobre la enseñanza de español en el país, una vez que el aprendizaje de este idioma cumple, entre otros aspectos, la función de posibilitar la ampliación de interacción en el contexto sociocultural multilingüe de los días actuales. 


\section{Referências}

BRASIL. Lei $n^{o}$ 4.024, de 20 dez. 1961. Estabelece a Lei de Diretrizes e Bases da Educação Nacional - LDB. Diário Oficial da União. Brasília, DF, 1961.

BRASIL. Lei $n^{o}$ 9.394, de 20 dez. 1996. Estabelece a Lei de Diretrizes e Bases da Educação Nacional - LDB. Diário Oficial da União. Brasília, DF, 1996.

BRASIL. Ministério da Educação. Secretaria de Educação Fundamental. Parâmetros Curriculares Nacionais (Ensino Médio). Linguagens, Códigos e suas Tecnologias. Brasília: MEC, 2000.

BRASIL. Lei $n^{o} 11.161$, de 05 ago. 2005. Dispõe sobre o ensino da língua espanhola. Diário Oficial [da] República Federativa do Brasil, DOU, Poder Executivo, Brasília, DF, 08 ago. 2005.

BRASIL. Orientações Curriculares para o Ensino Médio: Linguagens, códigos e suas tecnologias. Brasília: MEC/ Secretaria de Educação Básica, 2006.

BRASIL. Projeto Pedagógico do curso superior de Licenciatura em Letras-Espanhol (Modalidade EAD). Natal: IFRN, 2012.

BRASIL. Lei $n^{o}$ 13.415, de 16 de fev. de 2017. Altera as Leis $\mathrm{n}^{\circ}$ 9.394, de 20 de dezembro de 1996, que estabelece as diretrizes e bases da educação nacional, e 11.494, de 20 de junho 2007, que regulamenta o Fundo de Manutenção e Desenvolvimento da Educação Básica e de Valorização dos Profissionais da Educação, a Consolidação das Leis do Trabalho - CLT, aprovada pelo Decreto-Lei ${ }^{\circ} 5.452$, de $1^{\circ}$ de maio de 1943 , e o Decreto-Lei ${ }^{\circ}$ 236, de 28 de fevereiro de 1967; revoga a Lei ${ }^{\circ} 11.161$, de 5 de agosto de 2005; e institui a Política de Fomento à Implementação de Escolas de Ensino Médio em Tempo Integral.

BRASIL. Base Nacional Comum Curricular. Brasília: MEC/Secretaria de Educação Básica, 2018.

BRASIL. Projeto Pedagógico do curso superior de Licenciatura em Letras - Língua Espanhola e Literaturas (Modalidade presencial). Currais Novos: UFRN, 2018.

BRASIL. Projeto Pedagógico do curso superior de Licenciatura em Letras Espanhol (Presencial). Natal: IFRN, 2018.

CARVALHO, F. P. Representações dos professores de espanhol a respeito da lei federal n 11.161 e do ensino da língua após a sua promulgação. 2015. 185 f. Dissertação (Mestrado em Linguística Aplicada) - Faculdade de Letras, Universidade Federal de Minas Gerais, Belo Horizonte, 2015.

CARVALHO, T. L. de. La enseñanza de la escritura en ELE en la EaD brasileña: análisis y orientaciones didácticas. 2018, 322 f. Tese (Doctorado en Español: 
investigación avanzada en Lengua y Literatura) - Universidad de Salamanca, Salamanca, 2018.

CARVALHO, F. P. Possibilidades e (in)viabilidades do espanhol na educação básica: as leis da metade. Revista Caracol, São Paulo, n. 19, p.676-703, jan/jun. 2020.

CARVALHO, T. L. de; COSTA JUNIOR, J. V. L. da. Resistência e políticas linguísticas para o ensino de espanhol no Ceará: o cenário pós-revogação da lei 11.161/05. In: MOREIRA, G. L; PONTES, V. de O. A história do ensino do Espanhol no Ceará. Campinas, SP: Mercado de Letras, 2020 [no prelo].

FERNÁNDEZ, F. M. El español en Brasil. In: SEDYCIAS, J. (org.). O ensino do espanhol no Brasil: passado, presente, futuro. São Paulo: Parábola Editorial, 2005, p.1434.

GOMES, A. T.; FALCÃO, C. A.; IRINEU, L. M. Um raio-X do ensino de espanhol como língua estrangeira (E/LE) no Rio Grande do Norte (RN): políticas públicas, avanços e desafios. In: BARROS, C.; COSTA, E.; GALVÃO, J. Dez anos da "Lei do Espanhol" (2005-2015), 2016, pp. 293-306.

GUIMARÃES, A. História do ensino de espanhol no Brasil. Scientia Plena, v. 7, n. 11, p. 1-9, nov. 2011.

PARAQUETT, M. As dimensões políticas sobre o ensino da língua espanhola no Brasil: tradições e inovações. In: MOTA, K; SCHEYERL, D (orgs.). Espaços linguísticos: resistências e expansões. Salvador: EDUFBA, 2006.

SEDYCIAS, J. (org.). O ensino do espanhol no Brasil: passado, presente, futuro. São Paulo: Parábola Editorial, 2005.

SILVA JUNIOR, A. F. da; ERES FERNÁNDEZ, I. G. M. Ausência da língua espanhola na Base Nacional Comum Curricular: quais implicações esperar? In: GERHARDT, A. F. L. M; AMORIM, M. A. (orgs.). BNCC e o ensino de línguas e literatura. Campinas, SP: Pontes, 2019a.

SILVA JUNIOR, A. F. da; ERES FERNÁNDEZ, I. G. M. A docência de línguas estrangeiras e as políticas recentes para a formação inicial de professores. In: SOUZA, F. M. de; LENDL, A; COSTA JUNIOR, J. V. L da. (orgs.). Ensino de línguas na contemporaneidade: culturas, tecnologias e alteridades. São Paulo: Mentes Abertas, $2019 b$.

Recebido em 20 de maio de 2020

Aceito em 09 de julho de 2020 